\title{
Reusable Thermal History Sensing via Oxidation of a Divalent Rare Earth Ion Based Phosphor Synthesized by the Sol-Gel Process
}

\author{
Álvaro Yáñez González ${ }^{1}$, Stephen Skinner², Frank Beyrau ${ }^{1}$, Andrew Heyes ${ }^{3}$ \\ ${ }^{1}$ Department of Mechanical Engineering, Imperial College London, United Kingdom \\ ${ }^{2}$ Department of Materials, Imperial College London, United Kingdom \\ ${ }^{3}$ Energy Technology and Innovation Initiative, University of Leeds, United Kingdom
}

Address correspondence to Professor Andrew Heyes, Energy Technology and Innovation Initiative, University of Leeds, Leeds, LS2 9JT, United Kingdom. E-mail:

A.Heyes@leeds.ac.uk, Phone number: +44 (0)113 3435857. 


\section{ABSTRACT}

Temperature measurements in harsh environments, such as those present in gas turbines, are of great importance but very hard to obtain. Sometimes, on-line measurements are not possible, and instead, the temperatures during operation are recorded using so-called thermal history sensors and read offline. Although thermal paints have been used for many years as thermal history sensors, they present some disadvantages. Recently, a new method based on irreversible changes in the emission properties of phosphor materials when they are exposed to high temperatures has been proposed. It has been demonstrated that the process of oxidation from $\mathrm{Eu}^{2+}$ to $\mathrm{Eu}^{3+}$ is temperature sensitive up to $1400^{\circ} \mathrm{C}$. In this paper, we describe the manufacture of $B a M g A l_{10} O_{17}: E u$ (BAM:Eu) using a sol-gel process, and report optical properties interrogated after heat treatments in air and argon atmospheres, which confirm that after treatment in argon, the oxidation process can be reversed. This suggests a promising reusability of the phosphor as a thermal history sensor. A temperature dependent measurand based on the change of optical properties with temperature has been defined with a dynamic range from $700^{\circ} \mathrm{C}$ to $1100^{\circ} \mathrm{C}$. The effect of exposure time to a certain temperature on this measurand has also been addressed. 


\section{Introduction}

Temperature is a physical property which needs to be accurately measured in many engineering processes, and in particular in gas turbines, where temperatures above $1200^{\circ} \mathrm{C}$ may exceed material limits and degrade physical properties. An alternative to on-line measurements such as the ones made using thermocouples, are thermal history sensors.

Thermal history sensors can record the temperatures to which they are exposed during operation, such that these temperatures can be determined off-line. One example of this type of sensor are temperature indicating paints -or thermal paints- which are widely used in gas turbine development [1-5]. Although they have been used for many years, these paints present some drawbacks and reliable results are difficult to obtain. Main problems with the use of these paints are related to subtle colour changes with temperature that lead to poor resolution and great dependence on local conditions such as ambient illumination. Furthermore, many thermal paints contain components hazardous to health, such as chromium, lead and nickel cobalt.

Recently, Feist et al. [6] proposed an alternative technique based on irreversible changes in the luminescent properties of phosphors. Phosphors consist of a ceramic host material doped with rare-earth or transition metal ions which act as luminescent centres. When these materials are illuminated with UV light they exhibit phosphorescence that changes with temperature. When these changes are not permanent the phosphor returns to its initial state once the exposure to high temperatures ceases. These reversible changes to the luminescent properties of phosphors have been used to measure surface temperatures for many years [7-9], and also to evaluate the condition of the coatings in which they are embedded [10-12]. Recently, micrometre sized phosphor particles have also been used as tracers for planar fluid flow and temperature measurements [13, 14]. However, irreversible changes to the luminescent properties can also happen but have been often reported in 
relation to conditions in which the phosphor output is compromised and efforts focused on minimizing this degradation. One of the first studies to consider the use of irreversible changes in phosphors to measure history temperatures was reported in [15]. Here, the permanent amorphous-to-crystalline transformation in the phosphor structure proved the concept, but exhibited an important drawback: it required a customized manufacturing process since commercial manufacturers do not sell amorphous phosphors. A different physical process for thermal history sensing using commercially available phosphors was reported in [16]. In that work, degradation of three phosphors $-\mathrm{BaMgAl}_{10} \mathrm{O}_{17}: \mathrm{Eu}^{2+}$ (BAM:Eu), $\mathrm{BaMgAl}_{10} \mathrm{O}_{17}: \mathrm{Eu}^{2+}, \mathrm{Mn}^{2+}(\mathrm{BBG})$ and $\mathrm{SrAl}_{14} \mathrm{O}_{25}: \mathrm{Eu}^{2+}$ (SAE)- due to oxidation of divalent $\mathrm{Eu}$ to the trivalent state was proved for the first time to be suitable for temperature sensing up to $1400^{\circ} \mathrm{C}$. Their sensing abilities were related to the change in optical emission properties with the temperature to which they were exposed. According to these changes, an intensity ratio based on two different emission lines of the phosphors was defined and calibration curves over a certain temperature range were provided.

The oxidation concept proved to be promising in its use for thermal history sensing, and particularly for BAM:Eu. This phosphor is commonly used in plasma display panels (PDP) due to its high luminance efficiency in the blue region, and its degradation process has been extensively studied related to this application [17-23]. However, the conclusions derived from these studies need to be carefully considered, since those studies concentrated their attention in thermal degradation during manufacture and degradation in service under exposure to vacuum UV (VUV) irradiation. This implies that the duration of the phosphor exposure to high temperatures in previous investigations, which was $1 \mathrm{~h}$ or above, was longer than might be needed as a thermal history sensor. In addition, in most of the referred work excitation of the phosphor was achieved using VUV wavelength, typically the $147 \mathrm{~nm}$ of a Xenon lamp, which is shorter than the excitation that would be used in a thermal history 
phosphor application. This makes it difficult to compare photoluminescence results, since the emission spectra is dependent on the excitation used. Finally, the reported research shows a lack of agreement as to what is the exact degradation mechanism of the phosphor, although it seems to be related to the oxidation of $\mathrm{Eu}^{2+}$ to $\mathrm{Eu}^{3+}$ when the bath gas contains oxygen.

In order to use BAM:Eu as a thermal history sensor, more work is needed so that its degradation can be understood and characterised in terms of optical properties that can be used to obtain reliable and repeatable measurements. Similarly, it is important to investigate the manufacture of a phosphor coating. This will involve the careful choice of a binder since these may affect the luminescent emission and/or consideration of techniques for manufacturing coatings without any binder if it is shown that the binder hinders the optical emission of the phosphor material.

Current sensors are effectively single use since once they have been exposed and physical changes have occurred they cannot be reset. A desirable feature of thermal history sensors would be the possibility of reuse. Once the component has been exposed to high temperatures in operation and the temperature measured off-line, it would then be possible to reset the sensor to its initial condition so that new temperature measurements could be performed. For this to be effective, on each consecutive measurement the results should be repeatable and consistent.

In the present work, BAM:Eu phosphor powder was manufactured using a sol-gel process, with a view to creating a coating without any binder by the sol-gel dip coating method $[24,25]$. The concept of thermal history phosphor resetting was explored, and the manufactured BAM:Eu was degraded in air and then heat treated in an argon atmosphere. Investigation of optical properties before and after this heat treatment permitted identification of the oxidation state of the phosphor to confirm the possibility or otherwise of the resetting process. Optical properties of the phosphor have also been investigated with regards to 
temperature sensing. A suitable measurand for temperature sensing similar to the intensity ratio employed in previous studies [16] has been defined. The intensity ratio, based on the

relative intensities of two emission lines of the phosphor, has been calibrated for a temperature range from $700^{\circ} \mathrm{C}$ to $1100^{\circ} \mathrm{C}$, with repeatability better than $10^{\circ} \mathrm{C}$. The evolution of the intensity ratio, and therefore the degradation of the phosphor, has also been studied with regards to the exposure time at a constant temperature.

\section{Experimental procedures}

\section{Sol-gel manufacturing process}

Europium doped barium magnesium aluminate (BAM:Eu) powder was prepared using the sol-gel process and following a similar method to that reported in previous research $[26,27]$. A scheme of the procedure employed is shown in Figure 9. Aluminium nitrate nonahydrate (Alfa Aesar; No. 12360, 98\%), barium nitrate (Alfa Aesar; No. 30481, 99.95\%), magnesium nitrate hydrate (Alfa Aesar, No. 10799, 99.999\%) and europium(III) nitrate hydrate (Alfa Aesar, No. 11296, 99.99\%) were used as precursors. They were first dissolved in deionized water and then, a mass of citric acid equal to the weight of all metal precursors was added. Citric acid acted as the chelating agent. After stirring for 90 minutes, $5 \mathrm{ml}$ of ethylene glycol (Alfa Aesar, No. 44529) was added to the solution as the polymerizing agent. After that, the solution was heated on a hot plate at $100^{\circ} \mathrm{C}$ and stirred for $3 \mathrm{~h}$. The obtained product was a dried gel which was then heated in a furnace at $300^{\circ} \mathrm{C}$ for 90 minutes. The brown product obtained was then ground thoroughly and the resulting powder heated in air at $1200^{\circ} \mathrm{C}$ for $4 \mathrm{~h}$. The sample acquired a white colour and its structure was analysed using Xray diffraction (XRD). Its optical properties were also investigated at this point. After that, a heat treatment in an argon atmosphere at $1400^{\circ} \mathrm{C}$ for $4 \mathrm{~h}$ was performed. The optical properties of the sample were again interrogated after this step. 


\section{Sample preparation}

To study the optical properties of BAM:Eu related to degradation in air at different temperatures, a commercial BAM:Eu powder from Phosphor Technology was used. This powder sample shows the same photoluminescence properties as the BAM:Eu manufactured using the sol-gel process, as shown later in this paper.

Powder samples were heat treated in air at different constant temperatures and various times in order to investigate the effect of these two factors on the degradation of the phosphor. Firstly, a series of samples were heat treated at temperatures ranging from $700^{\circ} \mathrm{C}$ to $1100^{\circ} \mathrm{C}$ with constant treatment duration of 20 minutes. Secondly, another series of samples were treated in air at a constant temperature of $1000^{\circ} \mathrm{C}$ with treatment durations from 5 minutes to 60 minutes. Optical properties of these samples were then interrogated.

\section{Characterization}

The sample manufactured by the sol-gel process was analysed using XRD. The analysis was performed using $\mathrm{Cu} \mathrm{K} \alpha$ radiation (Bruker D2, Phaser) with the angle increasing in steps of $0.0322^{\circ}$ increments every $0.4 \mathrm{~s}$.

The photoluminescence properties of the phosphor powder were examined at room temperature for the sol-gel manufactured BAM and for each sample of the commercial BAM after annealing in air. Excitation of the phosphor was performed by the fourth harmonic (266 nm) of a pulsed Nd:YAG laser (Quanta-Ray LAB-150, Spectra Physics). Repetition rate was $10 \mathrm{~Hz}$, pulse width 5-7 ns and the maximum energy used was $5 \mathrm{~mJ}$. The beam was unfocused to avoid heating of the sample or other non-linear effects. The emission spectra were recorded using a $300 \mathrm{~mm}$ focal length Czerny-Turner type spectrometer (Acton SP-2300i, Princeton Instruments) with a grating groove of $300 \mathrm{~g} / \mathrm{mm}$. A $50 \mathrm{~mm}$ Nikon lens focused the emitted light onto the $10 \mu \mathrm{m}$ entrance slit of the spectrometer. At the exit slit, a CCD array camera measured the emission lines of the spectra with an exposure time of $0.1 \mathrm{~ms}$. Each of 
the recorded spectra consisted on an average of 75 single shot images. The CCD was independently wavelength calibrated in the spectral ranges centred at $450 \mathrm{~nm}$ and $610 \mathrm{~nm}$ using the emission lines of a mercury lamp. The wavelength resolution was less than $0.2 \mathrm{~nm}$. The CCD was previously intensity calibrated using a Tungsten lamp as constant light source.

\section{Results and discussion}

\section{BAM:Eu manufactured via sol-gel process}

The powder obtained after annealing in air was first investigated using XRD analysis to confirm the presence of BAM:Eu as the main phase. Photoluminescence properties were investigated for the powder after the two heat treatments in different atmospheres.

\section{$X$-Ray diffraction results}

The X-ray diffraction pattern of the powder annealed in air at $1200^{\circ} \mathrm{C}$ for $4 \mathrm{~h}$ is shown in Figure 10. Since the temperature of annealing is only $1200^{\circ} \mathrm{C}$, two different phases of the material are present, $\mathrm{BaAl}_{2} \mathrm{O}_{4}(\mathrm{BAL})$ and $\mathrm{BaMgAl}_{10} \mathrm{O}_{17}(\mathrm{BAM})$, which is in accordance with previous investigations [11]. The patterns agree with the standard patterns from the Joint Committee on Powder Diffraction Standard for BAM (ICDD Card No. 026-0163) and BAL (ICDD Card No. 017-0306), whose peaks are also shown in Figure 10 for comparison with the sample powder.

\section{Photoluminescence properties}

The sol-gel obtained phosphor powder was examined at room temperature after each heat treatment process to determine the oxidation state of Eu within the phosphor. Eu in the divalent state emits light in a broad band centred at around $445 \mathrm{~nm}$ corresponding to the $4 f^{6} 5 d \rightarrow 4 f^{7}$ transitions of $\mathrm{Eu}^{2+}$. When in the trivalent state, Eu emits light in several spectral 
features between $550 \mathrm{~nm}$ and $750 \mathrm{~nm}$ due to transitions from the ${ }^{5} \mathrm{D}_{0}$ to ${ }^{7} \mathrm{~F}_{\mathrm{J}}(\mathrm{J}=0,1,2,3,4)$ levels, the brightest peak being the one at $611 \mathrm{~nm}$ from the ${ }^{5} \mathrm{D}_{0} \rightarrow{ }^{7} \mathrm{~F}_{2}$ transition.

After annealing in air at $1200^{\circ} \mathrm{C}$, there was no observable emission at $450 \mathrm{~nm}$, corresponding to $\mathrm{Eu}^{2+}$. However, emission at $611 \mathrm{~nm}$ confirmed the presence of $\mathrm{Eu}$ in the trivalent state. After the powder was annealed in an argon atmosphere at $1400^{\circ} \mathrm{C}$, this emission at $611 \mathrm{~nm}$ almost completely disappeared while a broad band emission at $445 \mathrm{~nm}$ was now observable, as shown in Error! Reference source not found.. This confirmed that most of the Eu present in the trivalent form was reduced to the divalent state by means of a heat treatment under argon.

The manufactured $\mathrm{BAM}: \mathrm{Eu}^{2+}$ optical properties were compared with those of commercial BAM. Results are shown in Error! Reference source not found., where the spectrum of BAM:Eu manufactured by the sol-gel process after treatment in argon is compared with those of original commercial BAM and commercial BAM after annealing and resetting in an argon atmosphere. A small but noticeable blue-shift of about $3 \mathrm{~nm}$ can be observed in the commercial and sol-gel produced BAM samples after treatment in Argon with respect to the commercial, untreated BAM. This blue shift has been reported before when BAM is treated under reducing atmospheres $\left(\mathrm{N}_{2}\right.$ or $\left.\mathrm{H}_{2} / \mathrm{N}_{2}\right)$ [22], and it is thought to be related to the positions occupied by Eu atoms in the crystal structure. The effect of this $3 \mathrm{~nm}$ shift of the $\mathrm{Eu}^{2+}$ emission peak on temperature measurements is studied later on this paper.

Results shown in Error! Reference source not found. confirm that luminescent properties of the phosphor manufactured by the sol-gel process are similar to commercial BAM, and therefore following this result commercial BAM was subsequently used to study the sensing capabilities of BAM:Eu as a thermal history phosphor. 


\section{Study of sensing capabilities on commercial BAM}

The ability of BAM:Eu to perform as a thermal history sensor depends on identifying a measurand that changes continuously and monotonically over the temperatures range of interest (the dynamic range). An intensity ratio based on the photoluminescence spectral features of BAM:Eu has been proposed as the measurand and is discussed below.

\section{Definition of the intensity ratio}

Samples annealed in air at different temperatures have been examined at room temperature and the change of their emission spectra with annealing temperature has been recorded. As shown in Error! Reference source not found., both the broadband emission of $\mathrm{Eu}^{2+}$ at $445 \mathrm{~nm}$ due to $4 \mathrm{f}^{6} 5 \mathrm{~d} \rightarrow 4 \mathrm{f}^{7}$ transitions and the emission of $\mathrm{Eu}^{3+}$ around $611 \mathrm{~nm}$ due to ${ }^{5} \mathrm{D}_{0} \rightarrow{ }^{7} \mathrm{~F}_{2}$ transitions are observable after heat treatment above $700^{\circ} \mathrm{C}$. It is noticeable that the intensity of the peak corresponding to the $\mathrm{Eu}^{2+}$ emission decreases continuously with increasing annealing temperature whereas the intensity due to $\mathrm{Eu}^{3+}$ emission increases. The evolution of the intensity of each emission peak integrated over $10 \mathrm{~nm}$ under the curve is shown in Error! Reference source not found., where the intensity of $\mathrm{Eu}^{3+}$ is multiplied by a factor of 10 for visualization.

Now a ratio based on the change of the intensities of both emission lines can be defined, in a manner similar to that used for on-line phosphor temperature measurements. Here, a ratio was defined between the emission at $611 \mathrm{~nm}$ integrated over a $10 \mathrm{~nm}$ range centred at the peak and the emission at $445 \mathrm{~nm}$ also integrated over $10 \mathrm{~nm}$ and centred at the peak. This ratio represents a measurement similar to that which could be obtained with two optical spectral bandpass filters at the selected wavelengths and a FWHM of $10 \mathrm{~nm}$, as this is ultimately how it is envisaged that surface temperature history mapping could be performed. 
Evolution of intensity ratio with temperature and time

The ratio, as defined previously, has been calculated for the spectra of the samples treated at different temperatures for $20 \mathrm{~min}$ and it is shown in Error! Reference source not found. (left). The variation of the ratio with temperature follows an almost exponential behaviour, and increases from approximately $10^{-3}$ for a treatment temperature of $700^{\circ} \mathrm{C}$ to approximately $10^{\circ}$ for a temperature of $1100^{\circ} \mathrm{C}$. This means a continuous change of the ratio over three orders of magnitude, offering a dynamic range from $700^{\circ} \mathrm{C}$ to $1100^{\circ} \mathrm{C}$. In the left graph of Error! Reference source not found., in logarithmic scale, it can be observed an increase in the slope of the ratio at approximately $900^{\circ} \mathrm{C}$, which is thought to be related to the appearance of a second phase [20]. Therefore, the sensitivity of the sensor will be greater between $900^{\circ} \mathrm{C}$ and $1100^{\circ} \mathrm{C}$.

As stated before, there is a shift in the peak of the $\mathrm{Eu}^{2+}$ emission after the resetting treatment under argon. In order to analyse how this shift can affect the measured ratio and the sensed temperature, new calculations have been performed for all the samples. A shift of 3 $\mathrm{nm}$ in the integration range under the spectra was applied for the $\mathrm{Eu}^{2+}$ emission. The error induced in the temperature value measured by this shift is in all cases less than $1^{\circ} \mathrm{C}$.

In the plot on the right hand side of Error! Reference source not found., the evolution of the intensity ratio with heat treatment time is represented for a constant temperature of $1000^{\circ} \mathrm{C}$. The intensity ratio increases monotonically and almost linearly with time, which can be observed more clearly in Error! Reference source not found.. The ratio increases from approximately $5 \cdot 10^{-2}$ for a heat treatment duration of 5 minutes to nearly $10^{0}$ for a duration of 60 minutes, over one order of magnitude. The intensity ratio is clearly very sensitive to the duration of the heat treatment, and therefore careful calibrations of the ratio need to be performed with the same exposure time as intended in the actual measurement. 
Both results, from temperature dependent and time dependent ratio are consistent. In particular, there are two samples treated under the same conditions (i.e. 20 min and $1000^{\circ} \mathrm{C}$, see horizontal dashed line in Figure 7) that show ratio values of 0.2388 and 0.2511 , respectively. These two values correspond to a difference in the measured temperature of less than $2^{\circ} \mathrm{C}$, which reinforces the capability of this phosphor to perform as an accurate sensor.

\section{Conclusions}

The concept of thermal history sensor has been further investigated for the phosphor BAM:Eu with a sensitivity up to $1100^{\circ} \mathrm{C}$. Advantages relative to conventional thermal paints make this new sensor a potential candidate for use in gas turbines and therefore its manufacturing and sensing features are explored.

Sol-gel dip coating is considered to represent a feasible process to create phosphor coatings which can perform thermal history measurements without the use of any binder that could affect the optical properties of the phosphor. A BAM:Eu powder sample was manufactured using the sol-gel process. XRD analysis performed on the powder confirmed that the material obtained was formed of BAM.

Optical properties were investigated after heat treatments in air and argon atmospheres. After treatment at $1200^{\circ} \mathrm{C}$ in air all the Eu present in the sample was oxidised to the trivalent state. After that, the Eu was successfully reset to the divalent state via a heat treatment in an argon atmosphere. The spectral emission of the sol-gel manufactured powder was compared with that of commercial BAM, and the results confirmed that the optical properties of both materials were similar.

An intensity ratio dependent on heat treatment temperature and time was defined based on photoluminescence properties of BAM:Eu. This ratio exhibited sensitivity to temperature treatment and changed over 3 orders of magnitude from $700^{\circ} \mathrm{C}$ to $1100^{\circ} \mathrm{C}$, with 
repeatability of the ratio better than $10^{\circ} \mathrm{C}$. The ratio showed also sensitivity to the duration of the exposure to high temperatures, increasing over 1 order of magnitude when the treatment time increased from 5 min to 1 hour, underlining the suitability of the phosphor for this type of measurement.

Further work is being carried on with respect to the understanding of the resetting process and calibration of the sensor after successive implementations.

\section{Acknowledgements}

The authors would like to thank The Energy Futures Lab for the scholarship provided. The authors are also grateful for the assistance of Sensor Coating Systems Ltd in the use of some equipment.

\section{Nomenclature}

BAM Barium magnesium aluminate

PDP Plasma display panel

VUV Vacuum ultra violet

XRD X-ray diffraction

Nd:YAG Neodymium-doped yttrium aluminium garnet

CCD Charged-coupled device

ICDD International Centre for Diffraction Data

FWHM Full width at half maximum 


\section{References}

[1] Watson, H., and Hodgkinson, E., Temperature indicating paint, Patent US 10/229,002, 2002.

[2] Bird, C., Mutton, J., Shepherd, R., Smith, M., and Watson, H., Surface temperature measurements in turbines, in: AGARD Conference Proceedings, vol. 598, pp. 21.4$21.10,1998$.

[3] Smith, M., Interpretation of thermal paint, Patent US 6/434,267, 2002.

[4] Watson, H., and Hodgkinson, E., Method of analysing a temperature indicating paints using a marker paint, Patent US 10/760,529, 2004.

[5] Lempereur, C., Andral R., and Prudhomme, J. Y., Surface temperature measurement on engine components by means of irreversible thermal coatings, Measurement Science and Technology, vol. 19, 105501, 2008.

[6] Feist, J., Nicholls, J., and Heyes, A., Determining thermal history of components, Patent WO/2009/083,729, 2007.

[7] Allison, S. W., and Gillies, G. T., Remote thermometry with thermographic phosphors: Instrumentation and applications, Review of Scientific Instruments, vol. 68, no. 7 , pp. 2615-2650, 1997.

[8] Khalid, A. H., and Kontis, K., Thermographic phosphors for high temperature measurements: Principles, current state of the art and recent applications, Sensors, vol. 8, no. 9, pp. 5673-5744, 2008.

[9] Brubach, J., Pflitsch, C., Dreizler, A., and Atakan, B., On surface temperature 
measurements with thermographic phosphors: A review, Progress in Energy and Combustion Science, vol. 39, no. 1, pp. 37-60, 2013.

[10] Feist, J. P., and Heyes, A. L., Photo-Stimulated Phosphorescence for Thermal Condition Monitoring and Nondestructive Evaluation in Thermal Barrier Coatings, Heat Transfer Engineering, vol. 30, no. 13, pp. 1087-1095, 2009.

[11] Pilgrim, C. C., Berthier, S., Feist, J. P., Wellman, R. G., and Heyes, A. L., Photoluminescence for quantitative non-destructive evaluation of thermal barrier coating erosion, Surface and Coatings Technology, vol. 209, pp. 44-51, 2012.

[12] Steenbakker, R. J. L., Feist, J. P., Wellman, R. G., and Nicholls, J. R., Sensor Thermal Barrier Coatings: Remote In Situ Condition Monitoring of EB-PVD Coatings at Elevated Temperatures, Journal of Engineering for Gas Turbines and Power Transactions of the ASME, vol. 131, no. 4, 2009.

[13] Abram, C., Fond, B., Heyes, A. L., and Beyrau, F., High-speed planar thermometry and velocimetry using thermographic phosphor particles, Applied Physics B: Lasers and Optics, vol. 111, no. 2 pp. 155-160, 2013.

[14] Fond, B., Abram, C., Heyes, A. L., Kempf, A. M., and Beyrau, F., Simultaneous temperature, mixture fraction and velocity imaging in turbulent flows using thermographic phosphor tracer particles, Optics Express, vol. 20, no. 20 pp. 22118 22133, 2012.

[15] Rabhiou, A., Feist, J., Kempf, A., Skinner, S., and Heyes, A., Phosphorescent thermal history sensors, Sensors and Actuators A: Physical, vol. 169, no. 1, pp. 18-26, 2011.

[16] Rabhiou, A., Kempf, A., and Heyes, A., Oxidation of divalent rare earth phosphors 
for thermal history sensing, Sensors and Actuators B: Chemical, vol. 177, pp. 124$130,2013$.

[17] Sohn, K. S., Kim, S. S., and Park, H. D., Luminescence quenching in thermallytreated barium magnesium aluminate phosphor, Applied Physics Letters, vol. 81, no. 10, pp. 1759-1761, 2002.

[18] Kim, K. B., Koo, K. W., Cho, T. Y., and Chun, H. G., Effect of heat treatment on photoluminescence behavior of $\mathrm{BaMgAl}_{10} \mathrm{O}_{17}$ :Eu phosphors, Materials Chemistry and Physics, vol. 80, no. 3, pp. 682-689, 2003.

[19] Oshio, S., Matsuoka, B., Tanaka, S., and Kobayashi, H., Mechanism of luminance decrease in $\mathrm{BaMgAl}_{10} \mathrm{O}_{17}: \mathrm{Eu}^{2+}$ phosphor by oxidation, Journal of the Electrochemical Society, vol. 145, no. 11, pp. 3903-3907, 1998.

[20] Yamada, H., Shi, W. S., and Xu, C. N., Lattice deformation in thermally degraded barium magnesium aluminate phosphor, Journal of the Electrochemical Society, vol. 151, no. 12, pp. E349-E351, 2004.

[21] Bizarri, G., and Moine, B., On $\mathrm{BaMgAl}_{10} \mathrm{O}_{17}: \mathrm{Eu}^{2+}$ phosphor degradation mechanism: thermal treatment effects, Journal of Luminescence, vol. 113, no. 3, pp. 199-213, 2005.

[22] Kim, Y., and Kang, S., Investigation of the degradation mechanisms in $\mathrm{BaMgAl}_{10} \mathrm{O}_{17}: \mathrm{Eu}^{2+}$ phosphor: on the influence of thermal process on operational durability, Applied Physics B: Lasers and Optics, vol. 98, no. 2, pp. 429-434, 2010.

[23] Zhang, Z. H., Wang, Y. H., Li, X. X., Du, Y. K., and Liu, W. J., Photoluminescence degradation and color shift studies of annealed $\mathrm{BaMgAl}_{10} \mathrm{O}_{17}: \mathrm{Eu}^{2+}$ phosphor, Journal 
of luminescence, vol. 122, pp. 1003-1005, 2007.

[24] Brinker, C. J., Frye, G. C., Hurd, A. J., and Ashley, C. S., Fundaentals of sol-gel dip coating, Thin Solid Films, vol. 201, no. 1, pp. 97-108, 1991.

[25] Lin, J., Sanger, D. U., Mennig, M., and Barner, K., Sol-gel deposition and characterization of $\mathrm{Mn}^{2+}$-doped silicate phosphor films, Thin Solid Films, vol. 360, no. 1, pp. 39-45, Feb 2000.

[26] Lu, C. H., Chen, C. T., and Bhattacharjee, B., Sol-gel preparation and luminescence properties of $\mathrm{BaMgAl}_{10} \mathrm{O}_{17}: \mathrm{Eu}^{2+}$ phosphors, Journal of Rare Earths, vol. 24, no. 6, pp. 706-711, 2006.

[27] Sharma, P. K., Dutta, R. K., and Pandey, A. C., Performance of YAG:Eu ${ }^{3+}$, YAG: $\mathrm{Tb}^{3+}$ and $\mathrm{BAM}: \mathrm{Eu}^{2+}$ plasma display nanophosphors, Journal of Nanoparticle Research, vol. 14, no. 3, pp. 1-9, 2012. 


\section{List of Figure Captions}

Figure 1 Experimental method to prepare BAM:Eu phosphor via sol-gel process.

Figure $2 \mathrm{XRD}$ patterns for the powder sample after annealing in air at $1200^{\circ} \mathrm{C}$ for $4 \mathrm{~h}$. Main peaks of BAM and BAL are also shown for comparison.

Figure 3 Emission spectra of BAM:Eu manufactured by the sol-gel process after annealing in argon atmosphere at $1400^{\circ} \mathrm{C}$ for $4 \mathrm{~h}$. Excitation at $266 \mathrm{~nm}$.

Figure 4 Normalised $\mathrm{Eu}^{2+}$ emission spectra from BAM:Eu manufactured using the sol-gel process, commercial BAM and commercial BAM after resetting.

Figure 5 Spectra of BAM:Eu samples treated at different temperatures for $20 \mathrm{~min}$. Spectra corresponding to the $\mathrm{Eu}^{3+}$ emission is multiplied by a factor of 10 for better visualization. Curves at: $700^{\circ} \mathrm{C}, 800^{\circ} \mathrm{C}, 900^{\circ} \mathrm{C}, 950^{\circ} \mathrm{C}, 1000^{\circ} \mathrm{C}, 1050^{\circ} \mathrm{C}$ and $1100^{\circ} \mathrm{C}$.

Figure 6 Intensity variation of $\mathrm{Eu}^{2+}$ and $\mathrm{Eu}^{3+}$ emission peaks at $445 \mathrm{~nm}$ and $611 \mathrm{~nm}$ respectively, with treatment temperature. Emission of $\mathrm{Eu}^{3+}$ is multiplied by a factor of 10 for better visualization.

Figure 7 Intensity ratio variation with heat treatment temperature for a treatment time of 20 min. In the right insert, the variation of the intensity ratio with treatment time at $1000^{\circ} \mathrm{C}$ is shown.

Figure 8 Intensity ratio variation with heat treatment time at a constant temperature of $1000^{\circ} \mathrm{C}$. 


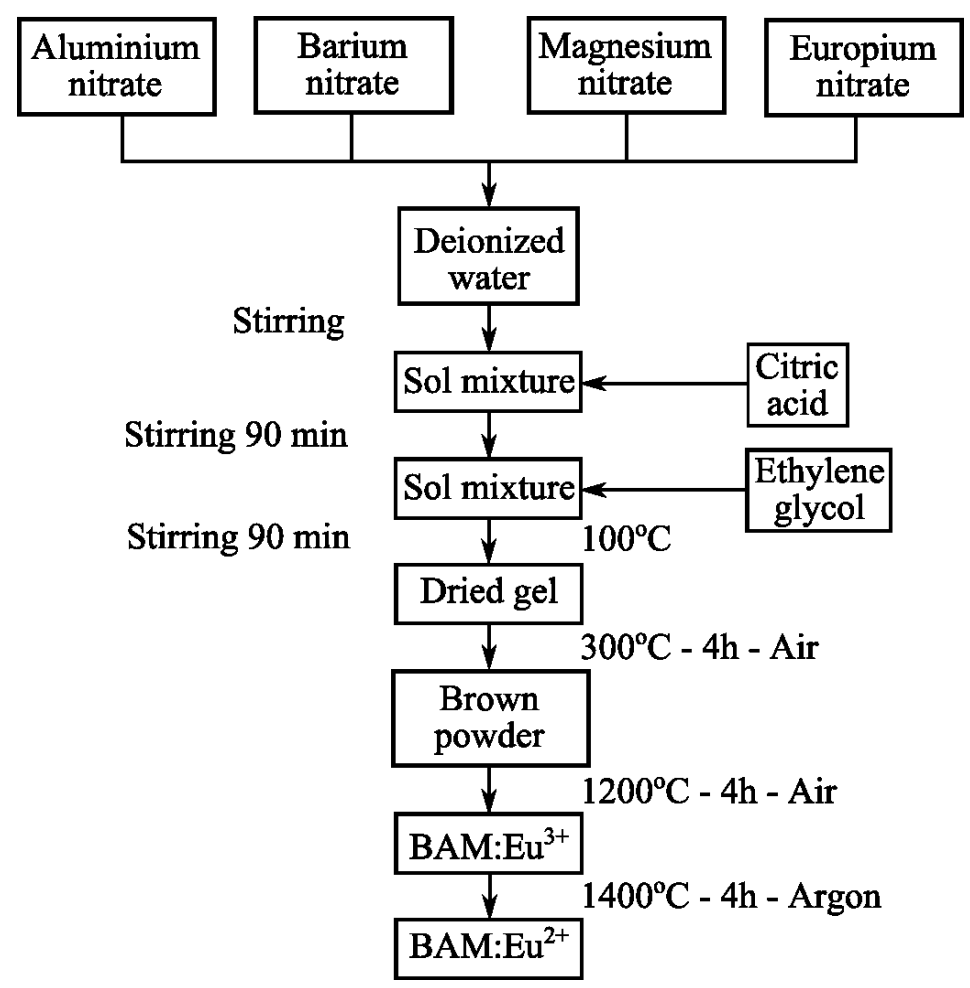

Figure 9 Experimental method to prepare BAM:Eu phosphor via sol-gel process. 


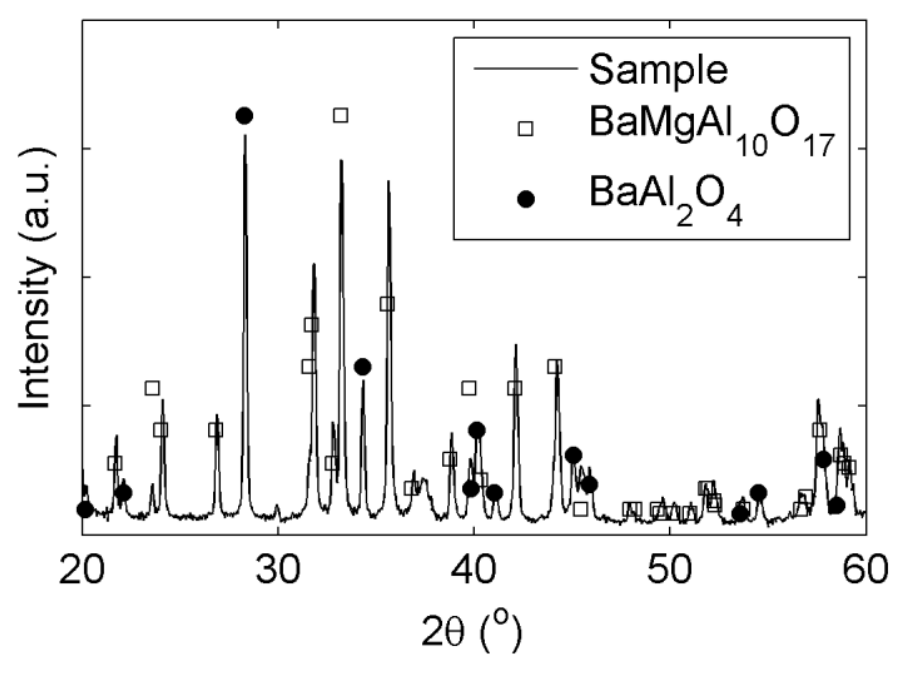

Figure $10 \mathrm{XRD}$ patterns for the powder sample after annealing in air at $1200^{\circ} \mathrm{C}$ for $4 \mathrm{~h}$. Main peaks of BAM and BAL are also shown for comparison. 


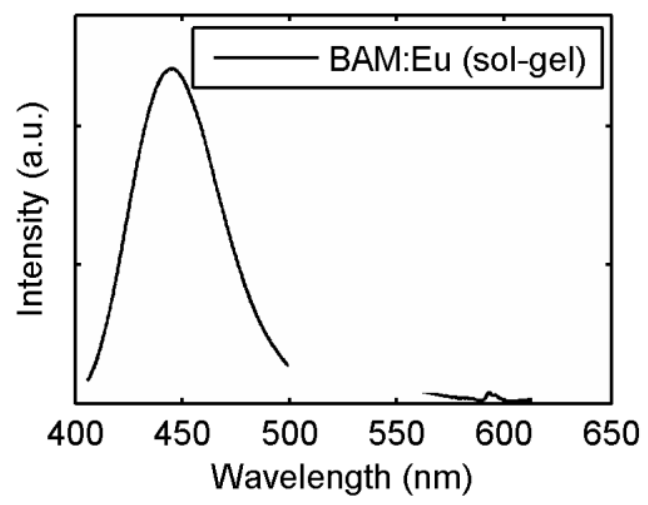

Figure 11 Emission spectra of BAM:Eu manufactured by the sol-gel process after annealing in argon atmosphere at $1400^{\circ} \mathrm{C}$ for $4 \mathrm{~h}$. Excitation at $266 \mathrm{~nm}$. 


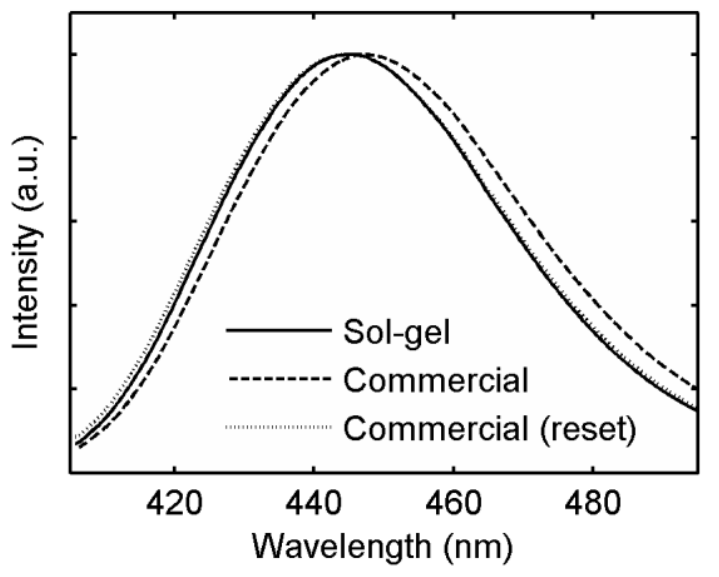

Figure 12 Normalised $\mathrm{Eu}^{2+}$ emission spectra from BAM:Eu manufactured using the sol-gel process, commercial BAM and commercial BAM after resetting. 


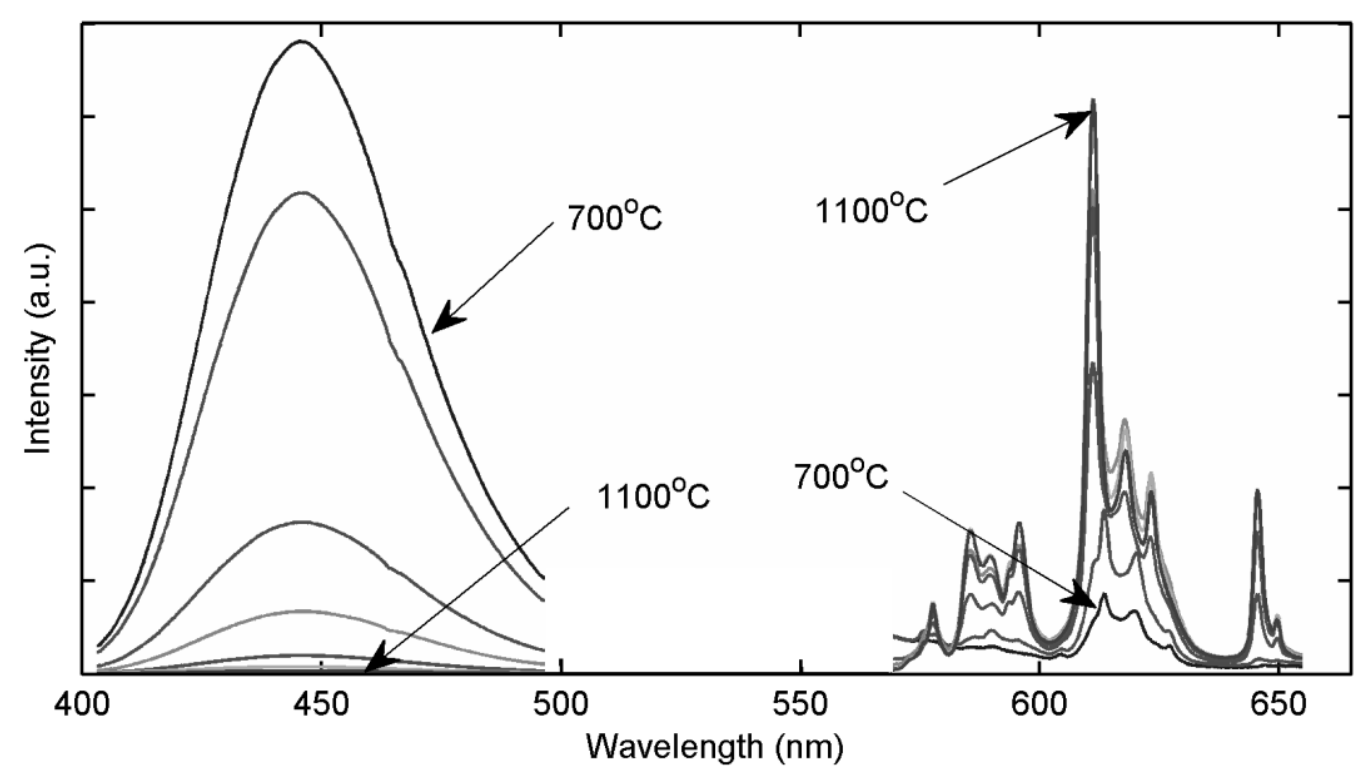

Figure 13 Spectra of BAM:Eu samples treated at different temperatures for $20 \mathrm{~min}$. Spectra corresponding to the $\mathrm{Eu}^{3+}$ emission is multiplied by a factor of 50 for better visualization. Curves at: $700^{\circ} \mathrm{C}, 800^{\circ} \mathrm{C}, 900^{\circ} \mathrm{C}, 950^{\circ} \mathrm{C}, 1000^{\circ} \mathrm{C}, 1050^{\circ} \mathrm{C}$ and $1100^{\circ} \mathrm{C}$. 


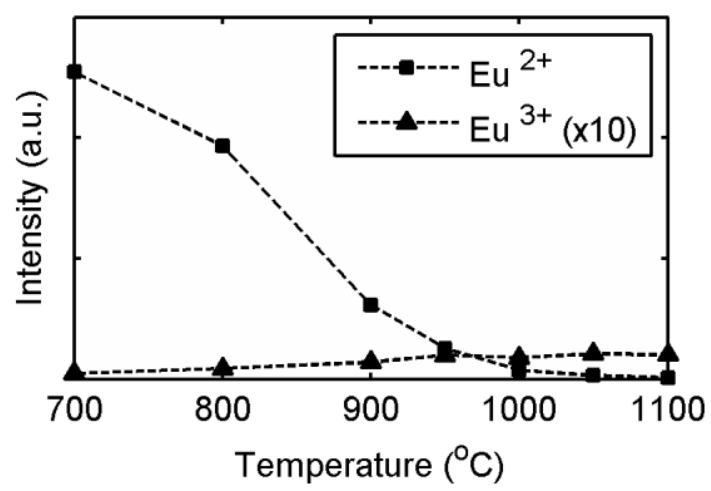

Figure 14 Intensity variation of $\mathrm{Eu}^{2+}$ and $\mathrm{Eu}^{3+}$ emission peaks at $445 \mathrm{~nm}$ and $611 \mathrm{~nm}$ respectively, with treatment temperature. Emission of $\mathrm{Eu}^{3+}$ is multiplied by a factor of 10 for better visualization. 


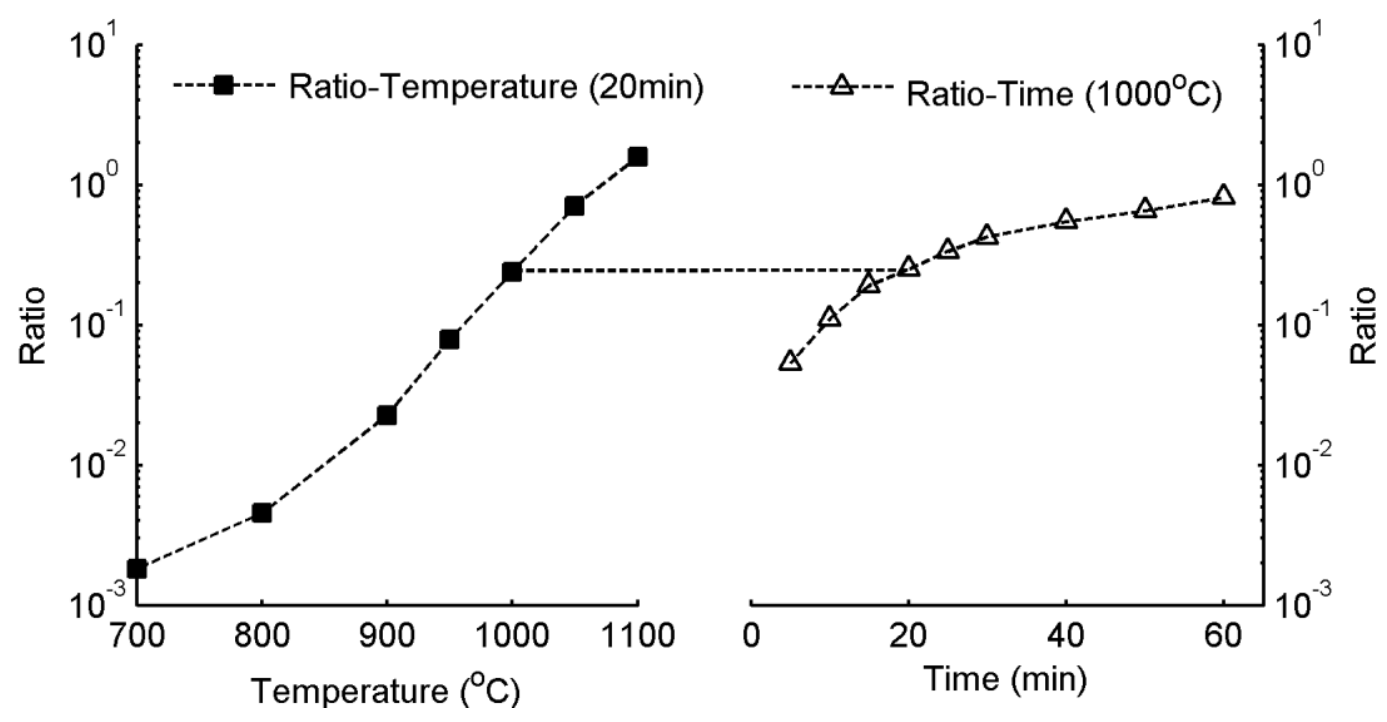

Figure 15 (Left) Intensity ratio variation with heat treatment temperature for a treatment time of $20 \mathrm{~min}$. (Right) Variation of the intensity ratio with treatment time at a constant temperature of $1000^{\circ} \mathrm{C}$. 


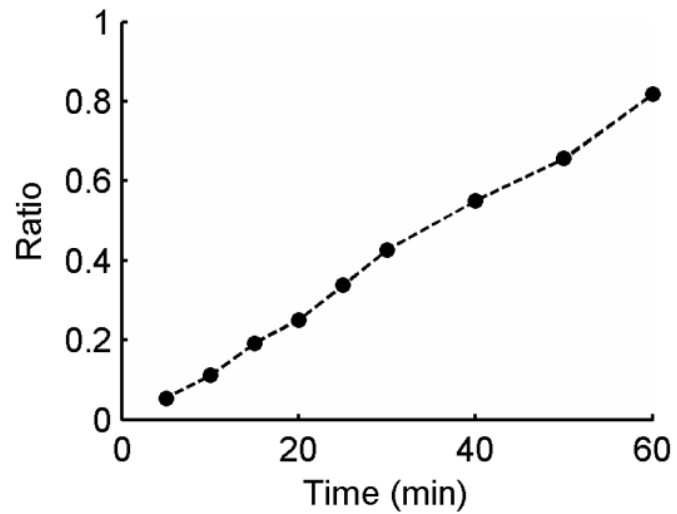

Figure 16 Intensity ratio variation with heat treatment time at a constant temperature of $1000^{\circ} \mathrm{C}$. 


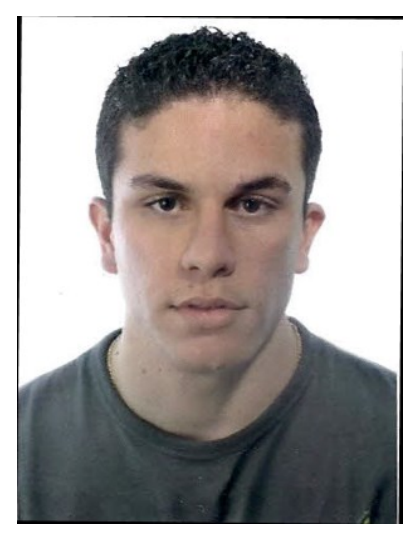

Álvaro Yáñez González is a $\mathrm{PhD}$ candidate in Mechanical Engineering at Imperial College London. He has a Licenciate degree (BSc+MSc) in Mechanical Engineering (2011) from Polytechnic University of Madrid, Spain. The study of BAM:Eu as a thermographic phosphor is the main subject of his thesis and his research interests lie in combustion sciences and thermometry.

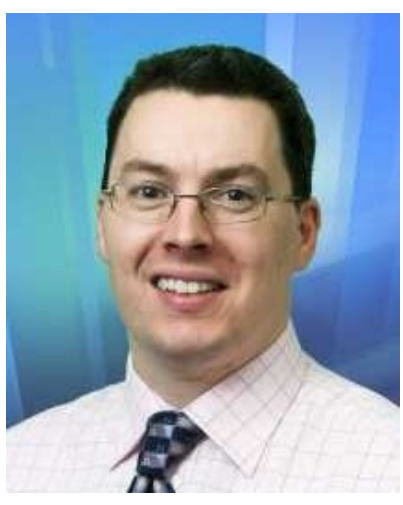

Stephen Skinner joined Imperial College in 1998 and was promoted to Reader in 2011. His research interests are in materials for new energy technologies and he is primarily concerned with the chemical and physical properties of potential solid oxide fuel cell electrolytes and electrodes and encompasses the electrical and structural characteristics of materials. His previous experimental experience includes the use of X-ray diffraction and spectroscopy, Mössbauer spectroscopy and materials synthesis.

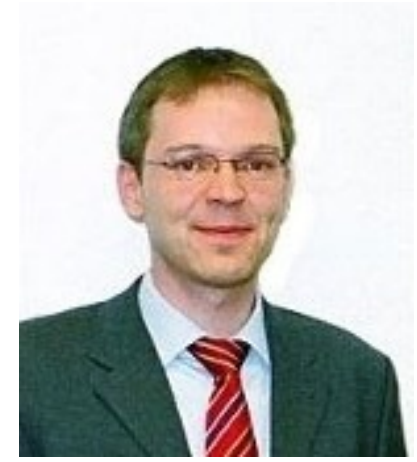

After his degree in Physics from Oldenburg University in Germany, Dr Beyrau did his $\mathrm{PhD}$ studies in Engineering Thermodynamics at the University of Erlangen-Nuernberg with the focus on laser spectroscopy for combustion analysis. After leading the group "combustion technology" at the same institute for 3 years he moved to Imperial College in 2008. The main focus of his research activities lies in the development and application of advanced laser diagnostics for the investigation of complex, reactive flows. Besides fundamental research in this field he also performs more 
applied investigations in cooperation with industry for the development of technical combustors, internal combustion engines and gas turbine processes.

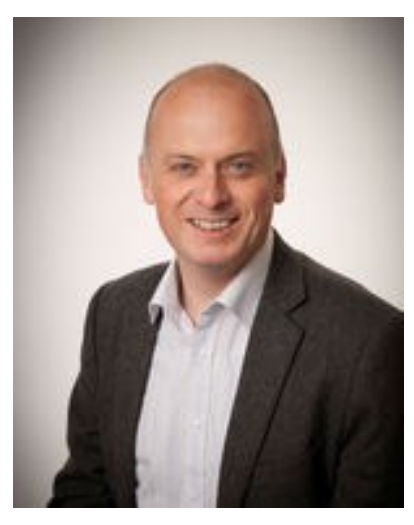

Professor Heyes studied Mechanical Engineering at the University of Manchester. He obtained a BEng degree in 1989 graduating with first class honours. He then went on the obtain an MSc in 1991 and $\mathrm{PhD}$ in 1994, also from Manchester, for development of the laser based Doppler Global Velocimetry optical flow diagnostic technique and the application of optical techniques for 3-D velocimetry in the vortical flow around a lifting delta wing at supersonic speeds. In $1992 \mathrm{Dr}$ Heyes joined Rolls Royce plc working in the Applied Science Laboratory on the development of optical diagnostic techniques for high temperature and reacting flows and on the gas dynamics of power station circuit breakers. In 1995 Dr Heyes moved to Imperial College London joining the Department of Mechanical Engineering as a lecturer in Thermofluids. He left Imperial in July 2013 as Reader in Heat Transfer, Deputy Director of the Energy Futures Laboratory and Director of the Sustainable Energy Futures masters programme. 